Topics in Chemical \& Material Engineering (TCME) 1(1) (2018) 127-129

ISBN: 978-1-948012-12-6 New Materials and Intelligent Manufacturing (NMIM)

\title{
DESIGN OF EXPERIMENTAL SYSTEM FOR AUTOMATIC INSTRUMENT BASED ON STEP
}

\author{
Jiayi Li' ${ }^{1}$, Yanan Meng' ${ }^{1}$, Dongxu Liu' ${ }^{2}$, Yupeng Zhai ${ }^{3}$
}

1 Department of Automation, Jilin Institute of Chemical Technology, Chengde Street, Jilin, China

2Department of Physical education, Jilin Institute of Chemical Technology, Chengde Street, Jilin, China

${ }^{3}$ Instrument workshop, PetroChina, Jilin Petrochemical Fertilizer Plant, Jilin, China

*Corresponding Author Email: 85169593@qq.com

This is an open access article distributed under the Creative Commons Attribution License, which permits unrestricted use, distribution, and reproduction in any medium, provided the original work is properly cited

\section{ARTICLE DETAILS}

\section{Article History:}

Received 26 June 2018

Accepted 2 July 2018

Available online 1 August 2018

\section{ABSTRACT}

An instrument experimental system is designed, which is used to measure several big parameters in the industrial process. The measuring parameters of the automatic experimental installation include liquid level, flow, temperature and pressure. It can realize the measurement of various instruments and common parameters in chemical industry and carry out the related verification experiments.

\section{KEYWORDS}

Instrumental, experimental installation, measurement

\section{INTRODUCTION}

In the automatic control system, the production process parameters are changed into electrical signals or air pressure signals to be displayed or recorded, so that people can understand the production process. It also needs to transmit signals to control instruments and devices to control the production process automatically and make the process parameters conform to the requirements. The automatic instrument experiment device is used to simulate the detection, transformation, field indication, transmission, and execution of the regulation unit directives by actuators. It is necessary to understand the basic knowledge of the automation instrument, such as the application of the instrument in the engineering, and master relevant practical skill [1].

\section{FLOW LEVEL INSTRUMENT SYSTEM}

The liquid flow level instrument system is shown in Figure 1. The system is composed of two flume and some pipes.

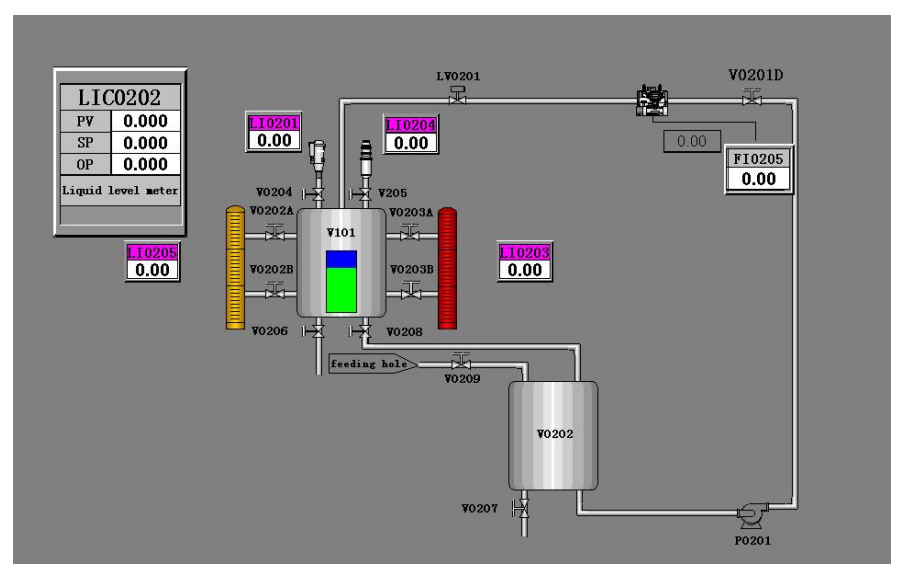

Figure 1: The liquid flow level instrument system

The normal temperature water in the flume V102 is knocked out by the pump P101, flowing through various flow meters into the flume V101.The water of the flume V101 flows through the bottom outlet to V102. Thus, a closed loop is formed. When entering the working state, it only selects one branches in the parallel path, other branches are closed through the valve. The system installed flow meter includes orifice meter, electromagnetic flow meter, glass rotameter and turbine flow meter. The liquid level instrument is installed in the flume V101 to detect liquid level, including the glass plate level gauge, the static pressure liquid level gauge and the ultrasonic liquid level gauge.

\section{TEMPERATURE INSTRUMENT SYSTEM}

The temperature instrument mainly includes thermal resistance thermometer and thermocouple thermometer with remote transmission function. The system is made up of a water tank with an armored thermal resistance thermometer (Pt100) and a thermocouple thermometer (division number is $\mathrm{K}$ ) inside. In the experiment, the water can be injected as a temperature source (20-80 degrees) and discharged through the valve F001. The output of the thermal resistance instrument is a three-wire signal, which sent the thermal resistance signal to the PLC directly. The output of the thermocouple instrument is millivolt signal and is sent to PLC through a terminal safety grating.

\section{PRESSURE INSTRUMENT SYSTEM}

The pressure instrument system consists of manual pressure source, pressure gauge and pressure transmitter. Turning the handle of the manual hydraulic source to generate the corresponding pressure signal during the experiment, the signal is output at the output port. Different types of pressure instruments are installed on the output port. They are general pressure meter, precision pressure meter, pressure transmitter with the remote transmission function, and the two-line signal produced by the instrument is sent to the monitoring computer.

\section{MONITORING SYSTEM}

The monitoring system of this experimental device adopts popular PLC monitoring mode. The signal produced by the actual instrument is sent to the terminal row and is connected to the I/O card of PLC through safety grating. Then PLC sends variables to the computer to monitor online. 


\section{HARDWARE SELECTION AND CONFIGURATION}

\subsection{Hardware selection}

The experimental system is designed with SIMATIC300 PLC. The specific modules are selected as follows.

PS (power module): 307 2A 6ES7 307-1BA00-0AA0, quantity 1.

CPU (memory): CPU 314 6ES7 314-1AG14-0AB0 quantity 1.

Memory card: 128KByte (MMC) 6ES7 953-8LG11-0AA0 quantity 1.

SM : 323 DI8/D08xDC24V/0.5A 6ES7 323-1BH01-0AA0 quantity 1.

SM : 331 AI8x13Bit 6ES7 331-1KF01-0AB0 quantity 4.

SM : 332 A04x12Bit 6ES7 332-5HD01-0AB0 quantity 1.

Ethernet communication module: CP 343-1 6GK7 343-1EX30-0XE0 quantity 1.

\subsection{Hardware configuration}

This design is programmed by SIMATIC-STEP7 software. According to the method of inserting the guide, it can be divided into a power module, a CPU module, an analog input and output module, and a digital input and output module on the guide rail. After inserting the module, click the button on the toolbar to save and compile the hardware configuration. Then the new project has been completed. STEP7 hardware configuration diagram is as shown in Figure 2.

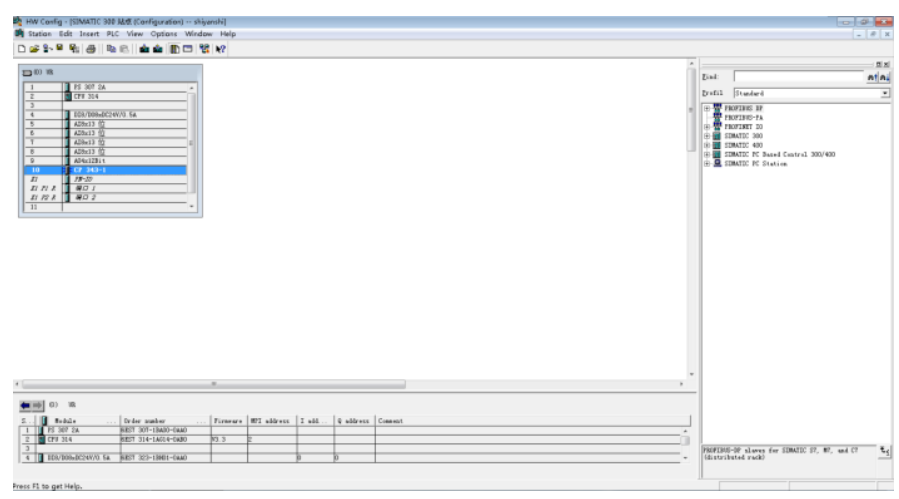

Figure 2: STEP7 hardware configuration diagram

\section{SYSTEM PROGRAMMING}

Combing the process requirements and the control scheme, a number of programs, such as analog input conversion program, analog output conversion program, digital control program, flow accumulation subprogram, main program has been written. The specific program is as follows.

\subsection{Analog input conversion program}

Actual quantities, such as pressure, temperature, flow, material level, etc., should be measured by various types of sensors. The analog input of the scene is converted into a voltage or current signal through the sensor. The signal is sent to FC105 module and converted to engineering scale and displayed $[2,3]$. Taking the indication signal of liquid level detection in V101 as an example, the implementation method of STEP7 software is shown in Figure 3.

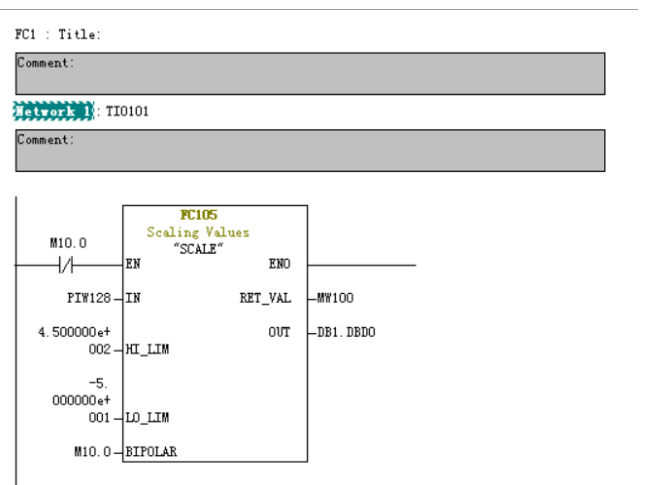

Figure 3: Liquid level display indication in V101 in STEP7

\subsection{Analog output conversion program}

The function of FC106 is to receive a real type input value (IN) between the lower and upper limits (LO_LIM and HI_LIM), which is indicated in an engineering unit, and convert it into an integer value. Write the results into OUT. The following is the control program of the V101 level control valve LV101, as shown in Figure 4.

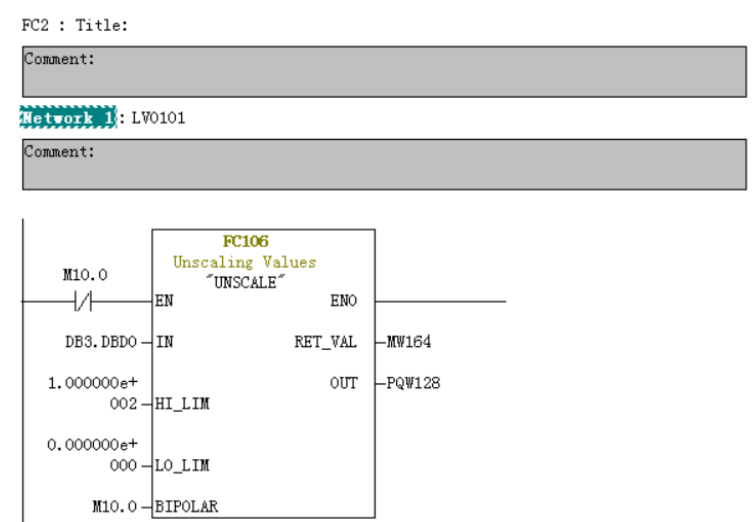

Figure 4: V101 level output regulation in STEP7

\subsection{Digital control program}

Digital input and output is directly controlled by signal line input to PLC or output from PLC to control field devices [4]. Taking the control of P101 intake pump as an example. P101 feed pump startup program in STEP7 is as shown in Figure 5.

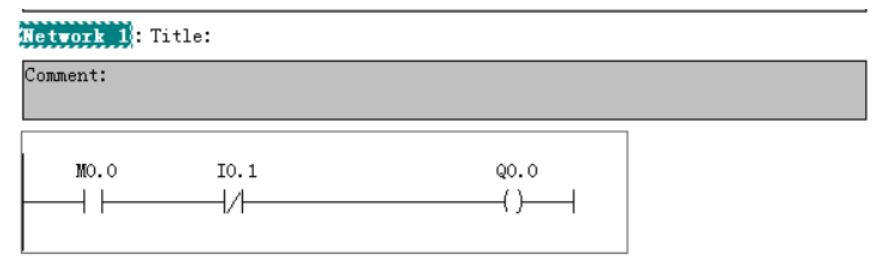

Figure 5: P101 feed pump startup program in STEP7

\subsection{Flow accumulation subprogram}

The principle of flow accumulative subprogram is the most primitive algorithm concept of integration, which multiplies the instantaneous flow in unit interval time by unit interval time, and gets the flow in unit interval time, then accumulates the flow rate by adding these small flows. Flow accumulation subprogram is as shown in Figure 6.

\begin{tabular}{|c|c|}
\hline L & \#pv \\
\hline $\mathrm{T}$ & \#iv_c \\
\hline L & \#iv_c \\
\hline L & \#ms_v \\
\hline$+\mathrm{R}$ & \\
\hline $\mathrm{T}$ & \#ns_v \\
\hline L & 荊s \\
\hline L & L\#1 \\
\hline$+I$ & \\
\hline T & \#ms \\
\hline L & L\#10 \\
\hline 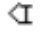 & \\
\hline $\mathrm{JC}$ & ol \\
\hline L & \#ns_v \\
\hline L & \#s_v \\
\hline$+\mathrm{R}$ & \\
\hline $\mathrm{T}$ & \#s_v \\
\hline L & \#s \\
\hline L & 1 \\
\hline$+\mathrm{I}$ & \\
\hline T & \#s \\
\hline L & 0 \\
\hline $\mathrm{T}$ & 荆s \\
\hline
\end{tabular}




\subsection{Main program}

OB1 is the main force of the STEP7 program. When the operating system is completed, it will start the loop to execute OB1 [5]. A subroutine can be called, such as analog input and output. The following is the main program in STEP7, as shown in Figure 7.

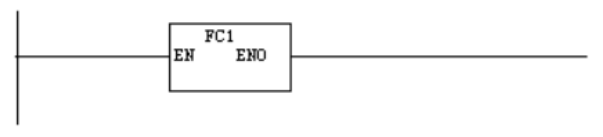

Hetwrk 2: Title:
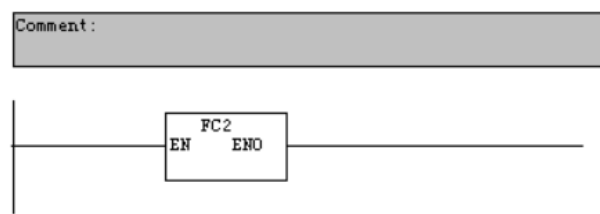

Hetwrk 3 : Title:

\section{Comment:}

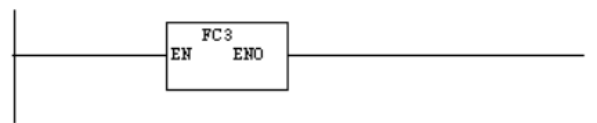

Figure 7: Main program in STEP7

\section{CONCLUSION}

Combined with practical application, this design can make the laboratory undertake more teaching tasks. The experiment that can be set up on the experimental device covers the knowledge points of the automation instrument, which is closer to the actual application of the field and has the value of practical training.
After the completion of the experimental device, it can not only undertake the teaching tasks of the related courses of automation and measurement and control technology and instrument, but also provide practical and practical training platform for the students to do specialty synthetic design, production practice and graduation design. It can provide a guarantee for practical teaching of the laboratory, and it has a good application prospect.

\section{REFERENCES}

[1] mHu, J. 2008. Engineering Application of SIEMENS S7-300/400PLC. Beijing: Beijing University of Aeronautics and Astronautics.

[2] Jian, C. 2007. SIEMENS S7 programmable controller: STEP Programming Guide. Xi'an: Mechanical Industry Press.

[3] Xu, D., Tong, J.S. 2001. Application technology of programmable controller PLC. Ji'nan: Science and Technology Publishing in Shandong.

[4] Ephrem, R.A., Mohammad, O.A. 2016. A review on the applications of programmable logic controllers (PLCs). Renewable and Sustainable Energy Reviews, 60, 1185-1205.

[5] Hong, Q.W. 2014. Power supply and grounding technique of PLC control system. Modern Electronics Technology, 7, 11-13.

\section{ABOUT THE AUTHORS}

Li Jiayi (1986-): Female, master degree, graduated from Jilin University in 2011, lecturer of Jilin Institute of Chemical Technology, mainly researching on control engineering, control theory and control system simulation.

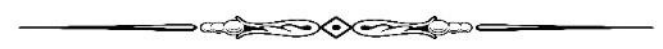

